\title{
ARTIFICIAL INTELLIGENCE, VIRTUAL REALITY AND ROBOTICS IN COLORECTAL SURGERY USING MASTER-CLASS TECHNOLOGICAL INNOVATIONS
}

\section{Salman Yousuf Guraya ${ }^{1 \otimes}$}

THIS ARTICLE MAY BE CITED AS: Guraya SY. Artificial intelligence, virtual reality and robotics in colorectal surgery using master-class technological innovations. Khyber Med Univ J 2021;13(2):5I-3. https://doi.org/10.35845/kmuj.2021.21578.

T he future of the surgical field can be envisioned by four leading technologies; robotics, genomics, artificial intelligence (Al) and augmented reality (AR). Of these, a major breakthrough is provided by $\mathrm{Al}$ which uses machine learning and other computer-based interfaces for augmenting the surgeons' decision making and the accuracy of surgical procedures.' Al imitates human cognitive functions by generating computational algorithms such as training and situation awareness, which can subsequently recreate human intelligence. ${ }^{2}$ Major challenges during surgical procedures for colorectal (CRC) include an accurate perception of cancer infiltration, the required depth and breadth of surgical dissection, mapping of the lymph node basin, and the identification and preservation of the surroundings vital structures. The need for $\mathrm{Al}$ is intensified in surgical oncology where surgeons need fine details of anatomical structures, precise tumor characteristics, and the degree of tumor infiltration into the primary organ and surrounding structures. ${ }^{3}$ Such features provide a roadmap to surgeons for defining the extent of surgical dissections for curative tumor resections as well as to mitigate the rate of potential complications which account for major morbidity in surgical patients. ${ }^{4}$ The use of $\mathrm{Al}$ in colorectal surgery allows the surgeons in surgical data extraction, surgical decisionmaking, an augmented execution of surgical steps and to reduce the rate of post-operative complications. In the surgical field, Al can support surgeons during the pre-, per-, and postoperative phases which ultimately lead to enhanced patient safety and less number of complications. Preoperatively, using machine learning, $\mathrm{Al}$ generates an algorithm that can reliably predict patient risk for developing complications in CRC, hepatobiliary and GIT surgical procedures. ${ }^{5}$ This computer generated calibration data also facilitates the surgeons to predict disease prognosis during surgeonpatient pre-operative discussions and in the decision-making process. A high rate of predicted complications, as suggested by $\mathrm{Al}$, would deter the surgeons to embark on a major surgical procedure.

Fluorescence image-guided surgery (FIGS) is an optical-based imaging which allows the visualization of structures otherwise invisible to surgeons intraoperatively. ${ }^{6}$ FIGS also permits an accurate assessment of the dynamic metabolic status of target organs such as colonic or pancreatic perfusion. This information aids the surgical decisionmaking by confirming the viability of the distal and proximal ends of the bowel. Further attractive clinical applications of FIGS include the identifcation of critical structures including bile ducts (fluorescence cholangiography), ureters, lymph nodes and even pelvic nerves using nerve-specific fluorophores. A variant of FIGS in the colonic perfusion assessment offers an intra-operative evaluation of the perfusion status of the anastomotic site. ${ }^{7}$ The use of a FIGS-based nearinfrared perfusion angiography has shown promising results with a very low rate of anastomotic leakage in CRC surgery. ${ }^{8}$ Further technogical developments in this field has provided tools that help in visualization of the vascular tree which enhances the
I: Member Editorial Board Khyber Medical University Journal, Vice Dean College of Medicine, University of Sharjah, United Arab Emirates.

Email冈: salmanguraya@gmail.com Contact \#: +97I-6-505727I (Off)

effectiveness and safety profile of surgical dissections and reduces operative time. ${ }^{9}$

An accurate understanding about the status of regional lymph nodes is vital to the surgeons before embarking on a colorectal procedures for CRC. The sentinel lymph node mapping using a subserosal injection of lymphazurin ${ }^{10}$ and an intra-operative radiochromoguided sentinel lymph node mapping by a gamma probe" have shown encouraging results. Recently, a onestep nucleic acid (OSNA) testing is introduced for a rapid histological analysis of the regional lymph nodes by the concurrent use of the near infrared laparoscopy and indocyanin green (ICG). ${ }^{12}$ OSNA is a powerful and reliable tool in helping surgeons in planning the extent of the surgical procedure.

During colorectal surgery, ureters are at risk of iatrogenic injuries, particularly for tumors with locoregional infiltrations and re-do surgeries. Traditionally, the intra-operative identification of the ureters is done by the insertion of a double J ureteric stent or an illuminated catheter. Recently, the intra-ureteric instillation of ICG dye facilitates the identification of ureters using an infrared arm of the laproscopic telescope. ${ }^{13}$ ICG binds with proteins of the ureteral epithelium and stains ureters for a long period of time. During the transanal total mesorectal excision (TME) of the rectal cancers, potential urehtral damage is a well-known complication with long-standing debilitation. Due to the close anatomical location of the prostate and urethra during TME, a fluorescent coated urethral catheter can potentially prevent urethral damage. The infra-red imaging using an 
optical device during surgery allows an accurate visualization of the underlying fluorescent coated urethral catheter. The fluorescent signals, emitting from the urethra, penetrate through thick layers of the urethra and provide a reliable identification throughout the length of the surgical procedure. These technological developments not only allow the surgeons to perform complex surgical procedures for advanced CRC, ${ }^{14}$ but also the surgeons can mentor junior trainees even through telementoring. ${ }^{15}$

Another advent in the field of surgical bioengineering is the robotic technology that carries a strong promise for enhanced patient safety, wider surgical exposure, and superior surgical control than the conventional laparoscopic tools. Surgical robots offer excellent ergonomics including highquality consoles which allow the surgeons to operate in a seated position and stable joystick controls with an ideal fulcrum effect. ${ }^{16}$ Additionally, the creation of haptic devices allows the reception of information from distal sensors. This telecommunication feature of the surgical robots enhances the proprioceptive power of surgeons during the dissection of tissues.

Due to growing concerns for patient safety and longer operating time during training, surgical education outside operating rooms has gained populartiy. The VR surgical simulation duplicates the operative field environment and, therefore, magnifies the impact of surgical training. VR simulation models provide both training and assessment opportunities for a wide range of surgical procedures worldwide. ${ }^{17}$ In sharp contrast to the animal modes, pre-recorded videos and e-learning platforms, VR simulators furnish a high fidelity climate with precise anatomical features exhibited in 3D graphics. Using VR simulators, learners manipulate skin, muscle, bone, nerve, bowel and blood vessels without the risk of damaging real patients' organs.

To conclude, the landscape of surgical oncology, particular colorectal surgery, is expanding. The developments of technical innovations using AI, VR and robotics have revolutionized colorectal surgery. Using modern tools, the scope of colorectal surgery has broadened in view of a superior peri-operative diagnosis and the precision of surgical procedures.

\section{REFERENCES}

I. Mirnezami R, Ahmed A. Surgery 3.0, artificial intelligence and the nextgeneration surgeon. $\mathrm{Br} J$ Surg $20 \mid 8$; I05 ( 5 ): $463-5$. https://doi.org//0.1002/bjs. 10860

2. Akkus Z, Galimzianova A, Hoogi A, Rubin DL, Erickson BJ. Deep learning for brain MRI segmentation: state of the art and future directions. J Digit Imaging $2017 ; 30$ ( 4$): 449-59$. https://doi.org//0.1007/s I02780l7-9983-4

3. Bodenstedt S, Wagner $M$, MüllerStich BP, Weitz J, Speidel S. Artificial Intelligence-Assisted Surgery: Potential and Challenges. Visc Med 2020;36(6):450-5. https://doi.org/ |0.||59/0005||35|

4. Khairy GA, Afzal MF, Murshid KR, Guraya S, Ghallab A. Post appendectomy small bowel obstruction. Saudi Med J 2005;26(7): 1058-60.

5. Merath K, Hyer JM, Mehta R, Farooq A, Bagante F, Sahara K, et al. Use of machine learning for prediction of patient risk of postoperative complications after liver, pancreatic, and colorectal surgery. J Gastrointest Surg $2020 ; 24$ ( 8 ) : $|843-5|$. https://doi.org/| 0.1007/s | | 605 019-04338-2

6. Diana M. Enabling precision digestive surgery with fluorescence imaging. Translational Transl Gastroenterol Hepatol 2017 Nov 21;2:97. https://doi.org/10.21037/ tgh.2017.1 I.06

7. Jafari MD, Wexner SD, Martz JE, McLemore EC, Margolin DA, Sherwinter DA, et al. Perfusion assessment in laparoscopic leftsided/anterior resection (PILLAR II): a multi-institutional study. J Am Coll Surg 20I5;220(I):82-92.el. https://doi.org/10.1016/j.jamcollsur

\section{g.2014.09.015}

8. Ris F, Hompes R, Cunningham C, Lindsey I, Guy R, Jones O, et al. Near-infrared (NIR) perfusion angiography in minimally invasive colorectal surgery. Surg Endosc 20 । $4 ; 28$ ( 7 ): 222 । - 6 . https://doi.org/10.1007/s004640I4-3432-y

9. Hirche C, Mohr Z, Kneif S, Doniga S, Murawa D, Strik M, et al. Ultrastaging of colon cancer by sentinel node biopsy using fluorescence navigation with indocyanine green. Int J Colorectal Dis $2012 ; 27$ ( 3 ): 3 । $9-24$. https://doi.org// 0.1007/s003840II-1306-5

10. Saha S, Wiese D, Badin J, Beutler T, Nora D, Ganatra B, et al. Technical details of sentinel lymph node mapping in colorectal cancer and its impact on staging. Ann Surg Oncol $2000 ; 7$ ( 2 ): 1 $20-4$. https://doi.org/10.1007/s I0434000-0I20-z

II. Nastro P, Sodo M, Dodaro C, Gargiulo S, Acampa W, Bracale U, et al. Intraoperative radiochromoguided mapping of sentinel lymph node in colon cancer. Tumori 2002;88(4):352-3.

12. Yeung TM, Wang LM, Colling R, Kraus R, Cahill R, Hompes R, et al. Intraoperative identification and analysis of lymph nodes at laparoscopic colorectal cancer surgery using fluorescence imaging combined with rapid OSNA pathological assessment. Surg Endosc 20 I8;32(2): 1073-6.

13. Kanabur P, Chai C, Taylor J. Use of indocyanine green for intraoperative ureteral identification in nonurologic surgery. JAMA Surgery 2020 ; I 55 ( 6 ): 520 - I. https://doi.org/10.100 I/jamasurg.2 020.0094

14. Guraya SY. Pattern, stage, and time of recurrent colorectal cancer after curative surgery. Clin Colorectal Cancer 2019;18(2):e223-8. https://doi.org/10.1016/j.clcc.2019. 01.003

15. Forgione A, Kislov V, Guraya SY, 
Kasakevich E, Pugliese R. Safe introduction of laparoscopic colorectal surgery even in remote areas of the world: the value of a comprehensive telementoring training program. J Laparoendosc Adv Surg Tech A 20 I 5;25(I):37-42.

16. Jayne D, Pigazzi A, Marshall H, Croft
J, Corrigan N, Copeland J, et al. Effect of robotic-assisted vs conventional laparoscopic surgery on risk of conversion to open laparotomy among patients undergoing resection for rectal cancer: the ROLARR randomized clinical trial. JAMA 2017;318(16):
1569-80. https://doi.org/10.100|/ jama.2017.7219

17. Li L, Yu F, Shi D, Shi J, Tian Z, Yang J, et al. Application of virtual reality technology in clinical medicine. Am J Transl Res 20I 7;9(9):3867-80.

\section{CONFLICT OF INTEREST}

Author declared no conflict of interest GRANT SUPPORT AND FINANCIAL DISCLOSURE

Author have declared no specific grant for this research from any funding agency in the public, commercial or not-for-profit sectors

KMUJ web address: www.kmuj.kmu.edu.pk Email address: kmuj@kmu.edu.pk 